\title{
Immunohistochemical characterization of (1) CrossMark the M4 macrophage population in leprosy skin lesions
}

\author{
Jorge Rodrigues de Sousa ${ }^{1,2}$, Francisco Dias Lucena Neto ${ }^{3}$, Mirian Nacagami Sotto ${ }^{4,5}$ and \\ Juarez Antonio Simões Quaresma ${ }^{1,2,3,5,6^{*}}$ (iD
}

\begin{abstract}
Background: Since macrophages are one of the major cell types involved in the Mycobacterium leprae immune response, roles of the M1 and M2 macrophage subpopulations have been well defined. However, the role of M4 macrophages in leprosy or other infectious diseases caused by mycobacteria has not yet been clearly characterized. This study aimed to investigate the presence and potential role of M4 macrophages in the immunopathology of leprosy.
\end{abstract}

Methods: We analyzed the presence of M4 macrophage markers (CD68, MRP8, MMP7, IL-6, and TNF-a) in 33 leprosy skin lesion samples from 18 patients with tuberculoid leprosy and 15 with lepromatous leprosy by immunohistochemistry.

Results: The M4 phenotype was more strongly expressed in patients with the lepromatous form of the disease, indicating that this subpopulation is less effective in the elimination of the bacillus and consequently is associated with the evolution to one of the multibacillary clinical forms of infection.

Conclusion: M4 macrophages are one of the cell types involved in the microbial response to M. leprae and probably are less effective in controlling bacillus replication, contributing to the evolution to the lepromatous form of the disease.

Keywords: Macrophage, Immunohistochemistry, Mycobacteria, Immunology

\section{Background}

Leprosy is a chronic infectious disease caused by Mycobacterium leprae, an obligate intracellular bacillus that infects macrophages, dendritic cells, and Schwann cells $[1,2]$. Leprosy is considered a neglected disease that represents a serious public health problem in developing countries [3, 4].

Clinically, leprosy shows spectral behavior in which the clinical evolution of the disease and associated histopathological changes are dependent on the host immune response. According to the Ridley-Jopling classification based on clinical, histopathological, immunological, and bacilloscopic criteria, leprosy presents in five main clinical

\footnotetext{
* Correspondence: juarez.quaresma@gmail.com

${ }^{1}$ Instituto Evandro Chagas, Secretaria de Vigilância em Saúde, Ministério da Saúde, Ananindeua, PA, Brazil

${ }^{2}$ Núcleo de Medicina Tropical, Universidade Federal do Pará, Belém, PA, Brazil Full list of author information is available at the end of the article
}

forms: tuberculoid leprosy (TT), borderline-tuberculoid leprosy (BT), borderline-borderline leprosy (BB), borderline-lepromatous leprosy (BL), and lepromatous leprosy (LL) $[5,6]$.

The clinical evolution of the disease is closely related with the immune response triggered in the host. Given the spectral nature of the disease, with well-defined clinical and immunological presentations at each stage, leprosy represents an efficient model for investigating the host-parasite relationship $[7,8]$. In the TT form, the cellular response is mediated by $\mathrm{T}$ helper (Th) 1 lymphocytes, which produce cytokines that induce a pro-inflammatory response. In the LL form, the cellular immune response is characterized by the predominance of Th2 lymphocytes, which trigger a suppressive response. In the forms BT, BB, and $\mathrm{BL}$, the cellular response presents a heterogeneous differentiation pattern that varies between the cellular responses in the TT and LL forms $[1,7,8]$. 
Previous studies have shown that according to the evolution or chronicity of spectral diseases, certain cell groups show a response that polarizes between pro- and anti-inflammatory activities. In this context, macrophages belong to a group of cells associated with the innate immune response that undergo phenotypic modification and produce receptors, co-stimulatory molecules, enzymes, and cytokines that induce the development of the suppressive or inflammatory response [9-11].

In the TT form of leprosy, activation of the classical pathway by M1 macrophages induces the production of tumor necrosis factor-alpha (TNF- $\alpha$ ), interferon-gamma (IFN- $\gamma$ ), and induced nitric oxide synthase (iNOS), which induce the generation of free radicals that destroy the bacillus [12]. Moreover, the LL form shows a predominance of M2 macrophages that induce the production of interleukin (IL)-10, transforming growth factor (TGF)- $\beta$, fibroblast growth factor (FGF)- $\beta$, arginase 1, CD209, CD163, and IDO, which contribute to the immunosuppressive response as well as tissue repair [13, 14].

There is growing evidence pointing to a new subpopulation of macrophages known as M4, which arise from M0 macrophages that change their behavior in the presence of CXCL4 to differentiate into M4 macrophages and produce CD68, IL-6, TNF- $\alpha$, MRP8, matrix metalloproteinase (MMP)7, and MMP12 [15-17]. The first study on M4 macrophages showed their predominance in atherosclerotic lesions, which increase the expression of receptors for low-density lipoprotein (LDL), thereby provoking the accumulation of oxidized LDL in phagocytes and ultimately causing the development of atheroma plaques and oxidative lesions [18].

Although it is known that macrophages are the main cells participating in the host immune response against $M$. leprae infection, the behavior of this new M4 subtype of macrophages and their potential influence on the development of the in-situ immune response in the leprosy spectrum remain unknown. Such information could help broaden the discussion about the immunopathogenesis of the disease. Therefore, we investigated the responses of M4 macrophages in the polar forms of leprosy.

\section{Materials and methods}

\section{Study design and participants}

Biopsy samples of 33 untreated patients (25 men and 8 women) at the Center of Tropical Medicine, Federal University of Para, and Dermatology Department of State University of Para with a confirmed diagnosis of leprosy that was made according to the classification of Ridley-Joplin were analyzed in this study; 18 patients had tuberculoid leprosy (TT) and 15 had lepromatous leprosy
(LL). All patients were from the state of Para, Brazil, and their mean age was 25.6 years.

\section{Histopathology and immunohistochemistry}

For histopathological analysis, 5- $\mu \mathrm{m}$ thick slices were prepared from tissue biopsies, embedded in paraffin, and stained with hematoxylin and eosin.

Tissue-specific staining was achieved through immunohistochemistry using the biotin-streptavidin-peroxidase method with antibodies against CD68 (CM033C; Biocare Medical, Pacheco/CA, USA), MRP8 (ab92331; Abcam, Cambridge/ MA, USA), MMP7 (ab205525; Abcam, Cambridge/MA, USA), IL-6 (ab154367; Abcam, Cambridge/MA, USA), and TNF- $\alpha$ (ab6671; Abcam, Cambridge/MA, USA). First, the tissue samples were deparaffinized in xylene and hydrated in a decreasing alcohol series. Endogenous peroxidase was blocked by incubating the sections in $3 \%$ hydrogen peroxide for $45 \mathrm{~min}$. For antigen retrieval, the sections were incubated in citrate buffer (pH 6.0) at $90{ }^{\circ} \mathrm{C}$ for $20 \mathrm{~min}$. Next, non-specific proteins were blocked by incubating the sections in $10 \%$ skim milk for $30 \mathrm{~min}$. The histological sections were then incubated with the primary antibodies diluted in $1 \%$ bovine serum albumin for $14 \mathrm{~h}$. Then, the slides were immersed in $1 \times$ phosphate-buffered saline (PBS) and incubated with the secondary biotinylated antibody [labeled streptavidin biotin (LSAB), Dako Cytomation] in an oven for $30 \mathrm{~min}$ at $37{ }^{\circ} \mathrm{C}$. The slides were again immersed in $1 \times$ PBS and incubated with streptavidin peroxidase (LSAB) for $30 \mathrm{~min}$ at $37{ }^{\circ} \mathrm{C}$. The reaction was developed with the addition of $0.03 \%$ diaminobenzidine plus $3 \%$ hydrogen peroxide as the chromogen solution. The slides were stained with Harris hematoxylin for $1 \mathrm{~min}$, dehydrated in an increasing alcohol series, and cleared in xylene. CD68 and MRP8 double staining was conducted on the same histological sections, using streptavidin alkaline phosphatase and diaminobenzidine and as a chromogenic substrate (yielding a pink reaction product), according to the protocol described by Azevedo et al. [19].

\section{Quantitative analysis and photodocumentation}

The immunohistochemical staining-positive areas were quantified using as a criterion of positivity the brownish deposit to coincide with macrophage morphology in the granulomatous infiltrate in the dermis. Immunostaining was quantified in five randomly selected fields that were visualized under an Axio Imager Z1 microscope (model $4,560,006$; Zeiss) at a magnification of $400 \times$ using a $0.0625-\mathrm{mm}^{2}$ grid with $10 \times 10$ subdivisions in the granulomatous inflammatory infiltrate, according to a previously described protocol [20-22]. 


\section{Statistical analysis}

Data were stored in electronic spreadsheets of the Excel 2007 program. Statistical analysis was performed using GraphPad Prism V.5.0. In univariate analysis, frequencies and measures of central tendency and dispersion were obtained. The Mann-Whitney t-test and Spearman correlation test were applied to test the hypotheses. A threshold significance level of $5 \%(p \leq 0.05)$ was adopted for all tests.

\section{Results}

\section{Characteristics of the study subjects}

The patients had altered tactile and thermal, and/or painful sensations on dermatoneurological examination. Patients with the TT form had cutaneous lesions consisting of erythematous or erythematous-hypochromic plaques with sharp edges and most anesthetic. Patients with the LL form had hypochromic spots and diffuse erythematous plaques and erythematous-violet or nodules that were infiltrated, bright, and sometimes coalescing. Histopathologically, the TT form was characterized by the presence of granulomas constituted of groups of epithelioid cells and sometimes surrounded by a dense or mild lymphocytic halo, with bacillus-negative status.
In the LL form, we observed granulomatous infiltrate consisting of histiocytes and plasma cells, extending along the entire upper dermis and surrounding the nerves and blood vessels, which could involve the deep dermis to the hypodermis and had bacillus positive status.

\section{Immunohistochemical characterization of M4 macrophages}

In tissue immunostaining, M4 macrophages were visible as depositions of brown-stained material in the cytoplasm or around cells, contrasting with the immunostaining-negative blue background (hematoxylin counterstaining). The presence of brown-stained areas coinciding with cell morphology was defined as a positive event. In the double staining experiment, brown-stained areas associated with pink-stained areas were areas positive for CD68 and MRP8. These criteria were adopted to minimize the counting of nonspecific staining, resulting in more accurate quantification.

Immunostaining for CD68 differed between the groups studied, with a significantly $(p<0.0001)$ lower median number of stained cells observed in the TT group (22.00 \pm 3.55 cells/field $)$ than in the LL group $(61.00 \pm 6.58$ cells/ field) (Figs. 1a, 2a and b). The median immuno-expression

\section{A}

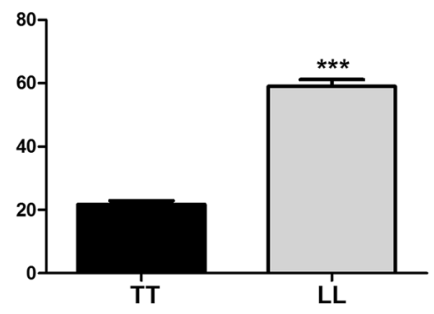

D

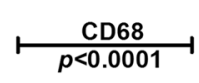

\section{B}

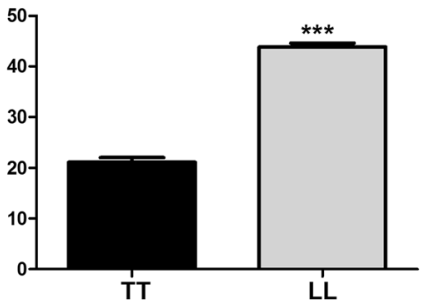

C
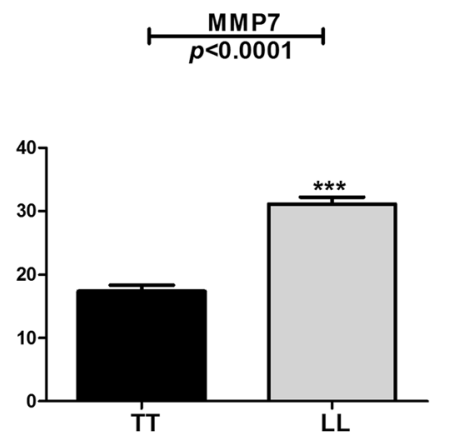

E
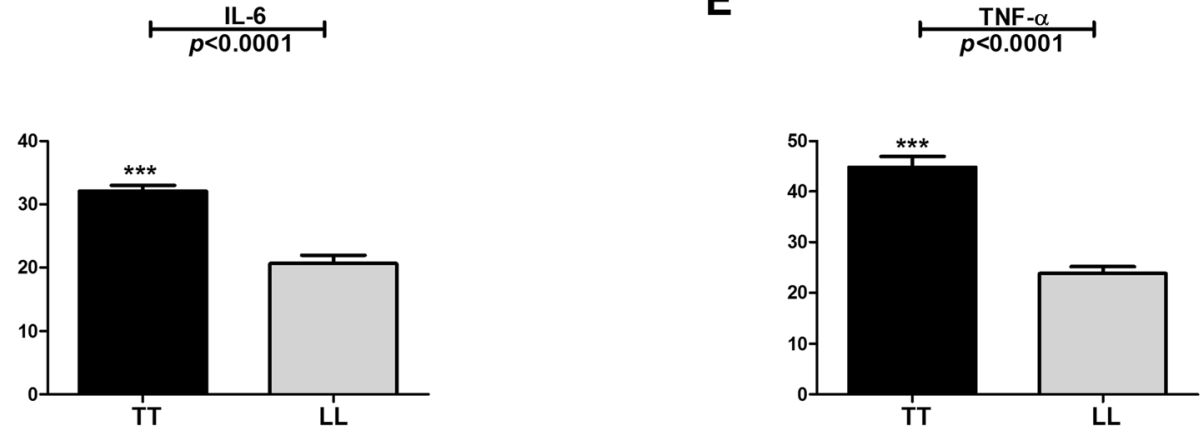

Fig. 1 Quantitative analysis for the immunostaining of CD68 (a), MRP8 (b), MMP7 (C) and IL-6 (d) and TNF-a (e) in TT and LL forms of leprosy 


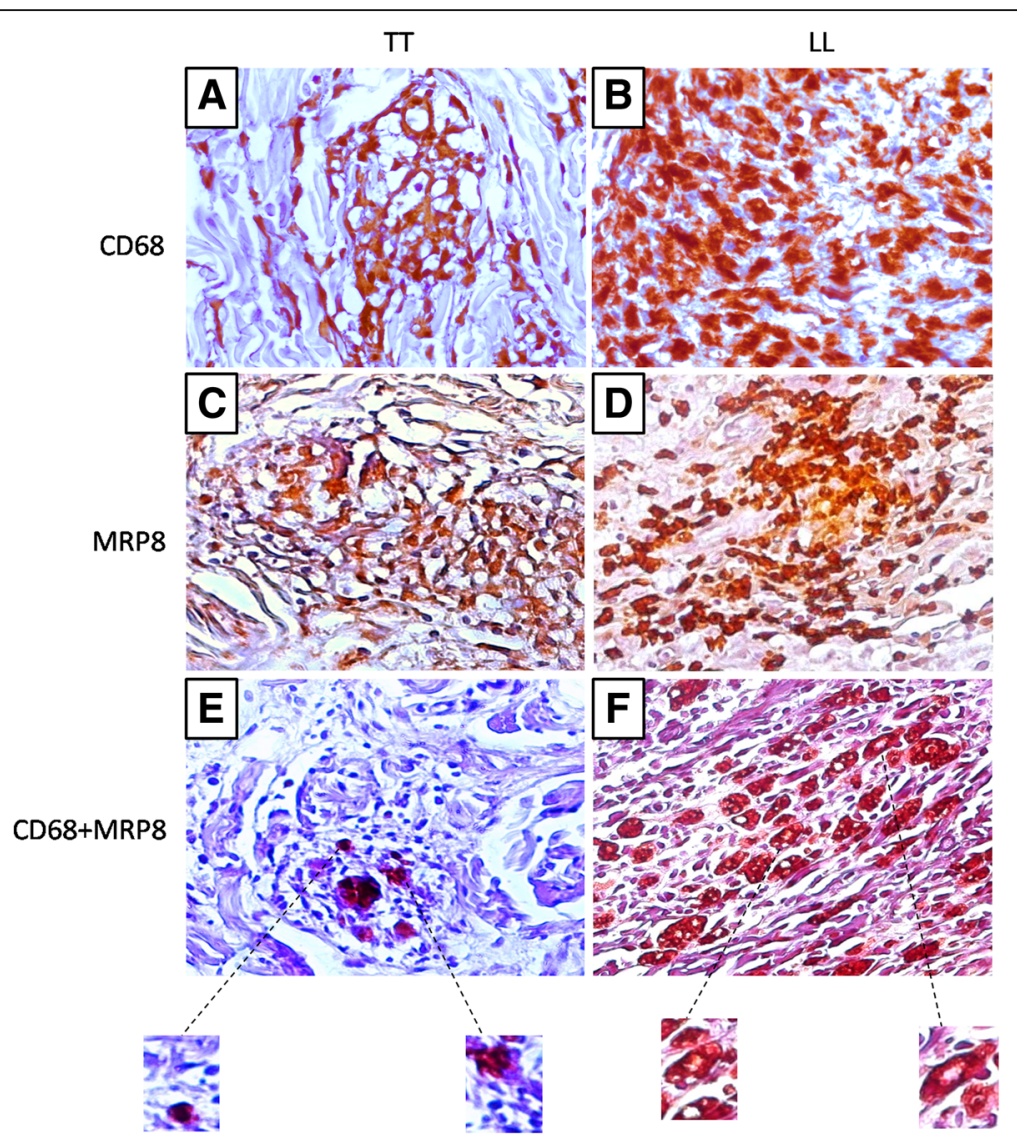

Fig. 2 Positive immunohistochemistry for CD68 (a: TT, b: LL), MRP8 (c: TT, d: LL) and double labeling for CD68/MRP8 (e: TT, f: LL) in TT and LL forms of leprosy

of MRP8 (Figs. 1b, 2c and d) and MMP7 (Figs. 1c, 3a and b) was also significantly (both $p<0.0001$ ) lower in the TT group (MRP8: $21.50 \pm 2.82$ cells/field, MMP7: $17.00 \pm 2.98$ cells/field) than in the LL group (MRP8: $44.50 \pm 2.57$ cells/field, MMP7: $31.50 \pm 3.44$ cells/field). However, the immuno-expression of IL-6 and TNF- $\alpha$ was significantly (both $p<0.0001$ ) higher in the TT group (IL-6: $32.00 \pm 2.76$ cells/field, TNF- $\alpha$ : $43.00 \pm 6.81$ cells/ field) than in the LL group (IL-6: $21.00 \pm 4.30 \mathrm{cells} /$ field, TNF- $\alpha: 24.00 \pm 4.21$ cells/field) (Figs. 1d, e, 3c-f). The double positive labeling for CD68 and MRP8 confirmed the presence of M4 macrophages in leprosy skin lesions (Figs. 2e and f).

Linear correlation analysis of immuno-expression in lesions of the TT and LL patients showed several positive associations, highlighting synergistic effects among CD68, MRP8, and MMP7 in the TT and LL forms (Table 1).

\section{Discussion}

Leprosy is an intriguing immunologic complex disease in which $M$. leprae causes granulomatous lesions and demyelination in the peripheral nerves [23, 24].
Leprosy is considered a spectral disease, with clinical and histopathological changes showing strong relationships with the pattern of the immune response triggered in the host $[6,25]$.

Macrophages belong to a select group of cells that differentiate, go through phenotypic modification, and participate in the microbicidal response in the activation of the classical pathway by M1 macrophages or in tissue repair in response to the action of M2 macrophages [26, 27]. Recently, the involvement of M4 macrophages in the pathogenesis of atherosclerosis has been recognized; however, the role of this new subtype in leprosy has not yet been investigated $[28,29]$.

The results obtained in the present study suggest that M4 macrophages have characteristics that imply they are probably ineffective in the microbicidal response to $M$. leprae, thus contributing to the development of clinical forms with more lesions and enhanced bacillary proliferation, as observed in the LL form. Within this context, the immunosuppressive behavior of M4 macrophages in inhibiting the microbicidal response [30,31] strongly suggests a possible 


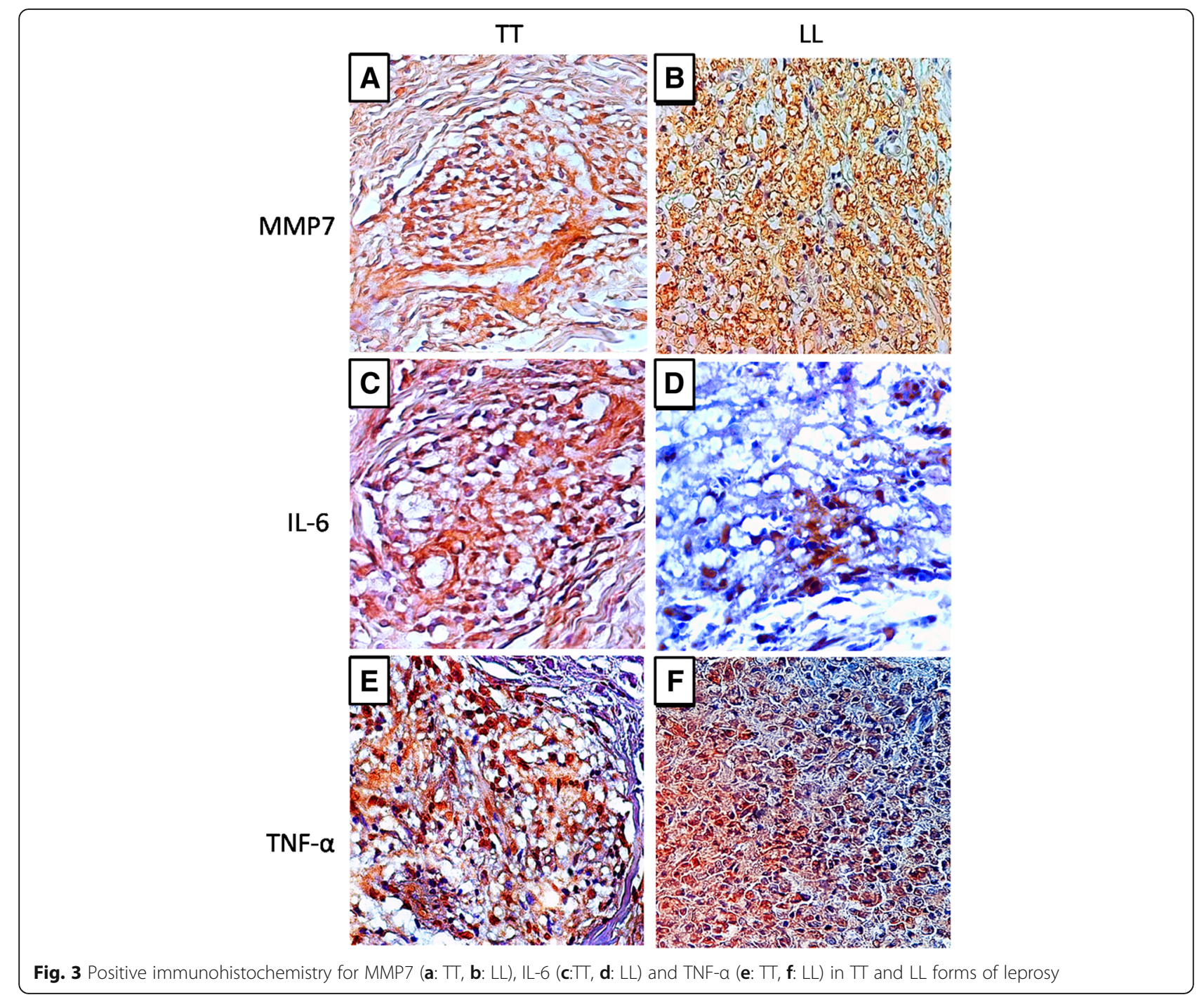

role in mediating the immune response in the LL form of disease.

The first report of the emergence of M4 macrophages showed that phagocytosis might be completely suppressed in these macrophages, which is likely directly related to the low expression of CD163, a scavenger receptor that recognizes hemoglobin/haptoglobin complexes [32]. In the LL form, this problematic characteristic of M4 macrophages might be crucial for maintaining the survival of the bacillus in the phagocytes owing to pathogen-triggered immune evasion. Therefore, the response of M4 macrophages as well as that of M2 macrophages suggests that the immunosuppressive environment established in the LL form of leprosy can restrict the microbicidal response to facilitate bacillus proliferation, resulting in more numerous lesions [13, 14].

Considering the cellular infiltrates, it is worth mentioning that the predominance of M4 macrophages in diseases such as atherosclerosis demonstrates that cells change their behavior favoring the appearance of foam cells and the development of an oxidative stress response inducing chemokine production and monocyte recruitment, thereby facilitating the accumulation of macrophages that express large amounts of LDL receptors $[33,34]$. One of the greatest challenges associated with immunopathological studies of the LL form lies in understanding the activity of macrophages and the differentiation mechanisms that influence their morphological patterns [35]. Through the numerous changes that occur in the tissue environment, Virchow's cells emerge as part of the adaptive process, which demonstrates that in the chronicity of the inflammatory response, macrophages lose the ability to destroy the bacillus, and lipid degeneration caused by the oxidative stress favors the appearance of foamy macrophages with vacuoles containing large numbers of bacilli [35-37]. Through the immunolabeling of markers that 
Table 1 Linear correlation analysis between markers that characterize the response of M4 macrophages in polar forms of leprosy

\begin{tabular}{lll}
\hline Correlation & $\pi$ & $\mathrm{LL}$ \\
\hline CD68 $\times$ MRP8 & $r=0.7796$ & $r=0.6821$ \\
& $p=0.0078^{* *}$ & $p=0.0298^{*}$ \\
CD68 $\times$ MMP7 & $r=0.6895$ & $r=0.7222$ \\
CD68 $\times$ IL-6 & $r=0.0312^{*}$ & $p=0.0183^{*}$ \\
CD68 $\times$ TNF-a & $p=0.6364$ & $r=0.0615$ \\
MRP8 $\times$ MMP7 & $r=0.6771$ & $p=0.8993$ \\
MRP8 $\times$ IL-6 & $p=0.0315^{*}$ & $r=0.7477$ \\
MRP8 $\times$ TNF-a & $r=0.6895$ & $p=0.0129^{*}$ \\
& $p=0.0312^{*}$ & $r=0.6604$ \\
MMP7 $\times$ IL-6 & $r=0.4458$ & $p=0.0377^{*}$ \\
& $p=0.1966$ & $r=0.2609$ \\
MMP7 $\times$ TNF-a & $r=0.2883$ & $p=0.4666$ \\
& $p=0.4191$ & $r=0.2050$ \\
TNF-a $\times$ IL-6 & $r=0.1734$ & $p=0.5700$ \\
& $p=0.6319$ & $r=0.1486$ \\
& $r=0.4939$ & $p=0.6820$ \\
& $p=0.1468$ & $r=0.2724$ \\
& $r=0.4644$ & $p=0.4463$ \\
& $p=0.1763$ & $r=-0.1111$ \\
& & $p=0.7599$ \\
\hline
\end{tabular}

characterize the response of M4 macrophages (CD68, S100A8, and MMP7), we observed a statistically significant difference in M4 macrophages in the LL form compared to the TT form.

Moreover, correlation analysis revealed an association between the expression of CD68, S100A8, and MMP7, which probably results in increased cellular activity in the polar disease forms. Of note, in the LL form, the expression of CD68, S100A8, and MMP7 was predominant in the inflammatory infiltrate composed of numerous foamy macrophages. The predominance of CD68 in the LL form of leprosy has been previously reported. Furthermore, the CD68 level is positively correlated with the production of iNOS in the microbicidal response in TT form of leprosy, which is one of the main enzymes that induce the production of $\mathrm{NO}$ and free radicals [38].

MRP8 (also known as S100A8 or calgranulin A) has been linked to numerous regulatory functions that modulate cell differentiation as well as phagocyte recruitment and activity $[39,40]$. MRP8 exhibits ambiguous behavior in response to Mycobacterium tuberculosis infection. In macrophages infected with $M$. tuberculosis, MRP8 formed a complex with MRP14 that facilitated bacillus survival [41]. In contrast, other studies have shown that macrophages infected with $M$. tuberculosis or M. leprae had increased MRP8 activity of the phagolysosome, mainly due to the response of IL-22 [42, 43].

MMP7 (also known as matrilisin) is a zinc- and calcium-dependent endopeptidase that degrades the extracellular matrix and regulates various cellular processes, including cellular proliferation, tissue remodeling, the inflammatory response, and apoptosis $[44,45]$. In an attempt to control the environment of tissue stress, increased MMP7 expression may mediate the tissue repair response by acting together with other cytokines, such as TGF- $\beta$ and NGF, to promote tissue regeneration, and thus avoid the development of multiple lesions that are characteristic of LL clinical form $[46,47]$.

Finally, we investigated the expression levels of IL-6 and TNF- $\alpha$ in the TT and LL forms of the disease, and we found that both IL- 6 and TNF- $\alpha$ are increased in the TT form. Classically, IL- 6 and TNF- $\alpha$ are considered to be cytokines that are strongly associated with the development of the M1 macrophage response and induction of the microbicidal response. In the TT form, these cytokines also participate in the responses of the lymphocytes Th1, Th17, and Th22, thereby aggravating the tissue damage [43, 46, 47].

\section{Conclusion}

Our study demonstrated that the presence of M4 macrophages in the LL skin lesions may be involved in an infective immune response and consequently the survival of $M$. leprae. Previous findings on the pathogenesis of atherosclerosis and the formation of vacuolated macrophages morphologically similar to Virchow's cells support our immunohistopathological findings in the LL form of leprosy. Our data also suggest that these cells can induce the establishment of a regenerative environment and remodeling of the extracellular matrix, which are important for the pathogen-host interaction during infection by $M$. leprae. Further studies in experimental models are needed to elucidate the detailed mechanisms underlying the roles of M4 macrophages in the pathogenesis of leprosy lesions and provide further insights into the disease spectrum.

\section{Acknowledgements}

We thank the Department of Dermatology and Leprosy Service of Para State University for support in this study.

\section{Funding}

Dr. Juarez A. S. Quaresma is a Research Productivity Fellow and Senior Postdoctoral Fellow at the Brazilian National Council for Scientific and Technological Development - CNPq/Brazil (grants number 302553/ 2015-0 and 116427/2016-7)

\section{Availability of data and materials}

The datasets used and/or analyzed in the current study are available. from the corresponding author on reasonable request.

\section{Authors' contributions}

JRS, FDLN, MNS, and JASQ contributed to research design, JRS and FDLN were involved in data acquisition and JRS, MNS, and JASQ were involved in data analysis and interpretation. All authors were involved in drafting and/or critically revising of the manuscript, and all authors approved the submitted final version. 


\section{Ethics approval and consent to participate}

All clinical investigations were conducted according to the principles expressed in the Declaration of Helsinki and Resolution No. 466/2012 of the National Health Council of Brazil. After a complete description and explanation of the study design, written informed consent was obtained from all participants. The study was approved by the Ethics Committee of Tropical Medicine Center, Federal University of Pará (protocol number 2.338.865).

\section{Consent for publication}

Not applicable.

\section{Competing interests}

The authors declare that they have no competing interests.

\section{Publisher's Note}

Springer Nature remains neutral with regard to jurisdictional claims in published maps and institutional affiliations.

\section{Author details}

'Instituto Evandro Chagas, Secretaria de Vigilância em Saúde, Ministério da Saúde, Ananindeua, PA, Brazil. ${ }^{2}$ Núcleo de Medicina Tropical, Universidade Federal do Pará, Belém, PA, Brazil. ${ }^{3}$ Centro de Ciências Biológicas e da Saúde, Universidade do Estado do Pará, Belém, PA, Brazil. ${ }^{4}$ Faculdade de Medicina, Universidade de São Paulo, São Paulo, SP, Brazil. Instituto de Medicina Tropical de São Paulo, Universidade de São Paulo, São Paulo, SP, Brazil. ${ }^{6}$ Núcleo de Medicina Tropical, UFPA, Av. Generalíssimo Deodoro 92, Umarizal, Belém, Pará 66055-190, Brazil.

Received: 27 March 2018 Accepted: 31 October 2018 Published online: 15 November 2018

\section{References}

1. Sousa JR, Pagliari C, de Almeida DS, Barros LF, Carneiro FR, Dias LB Jr, Souza Aarão TL, Quaresma JA. Th9 cytokines response and its possible implications in the immunopathogenesis of leprosy. J Clin Pathol. 2017;70:521-7.

2. Ogawa R, Hsu CK. Mechanobiological dysregulation of the epidermis and dermis in skin disorders and in degeneration. J Cell Mol Med. 2013;17:817-22.

3. Global leprosy update. 2016: accelerating reduction of disease burden. Wkly Epidemiol Rec. 2017:92:501-19.

4. Assembly WH. Global leprosy update, 2015: time for action, accountability and inclusion. Wkly Epidemiol Rec. 2015;91:405-20.

5. Talhari C, Talhari S, Penna GO. Clinical aspects of leprosy. Clin Dermatol. 2015;33:26-37.

6. Ridley DS, Jopling WH. Classification of leprosy according to immunity: a five-group system. Int J Lepr Other Mycobact Dis. 1966;34:255-73.

7. Aarão TL, Esteves NR, Esteves N, Soares LP, Pinto Dda S, Fuzii HT, Quaresma JA. Relationship between growth factors and its implication in the pathogenesis of leprosy. Microb Pathog. 2014;77:66-72.

8. Aarão TL, de Sousa JR, Botelho BS, Fuzii HT, Quaresma JA. Correlation between nerve growth factor and tissue expression of IL-17 in leprosy. Microb Pathog. 2016;90:64-8.

9. Mills CD. M1 and M2 macrophages: oracles of health and disease. Crit Rev Immunol. 2012;32:463-88.

10. Ouedraogo R, Daumas A, Ghigo E, Capo C, Mege JL, Textoris J. Whole-cell MALDI-TOF MS: a new tool to assess the multifaceted activation of macrophages. J Proteome. 2012;75(18):5523-32.

11. Mosser DM, Edwards JP. Exploring the full spectrum of macrophage activation. Nat Rev Immunol. 2008;8:958-69.

12. Simoes Quaresma JA, de Almeida FA, de Souza Aarao TL, de Miranda Araujo Soares LP, Nunes Magno IM, Fuzii HT, Feio Libonati RM, Xavier MB, Pagliari C, Seixas Duarte MI. Transforming growth factor $\beta$ and apoptosis in leprosy skin lesions: possible relationship with the control of the tissue immune response in the Mycobacterium leprae infection. Microbes Infect. 2012;14:696-701.

13. Sousa JR, Sousa RP, Aarão TL, Dias LB Jr, Carneiro FR, Fuzii HT, Quaresma JA. In situ expression of M2 macrophage subpopulation in leprosy skin lesions. Acta Trop. 2016;157:108-14.

14. Moura DF, de Mattos KA, Amadeu TP, Andrade PR, Sales JS, Schmitz V, Nery JA, Pinheiro RO, Sarno EN. CD163 favors Mycobacterium leprae survival and persistence by promoting anti-inflammatory pathways in lepromatous macrophages. Eur J Immunol. 2012;42:2925-36.

15. Chistiakov DA, Bobryshev YV, Orekhov AN. Changes in transcriptome of macrophages in atherosclerosis. J Cell Mol Med. 2015;19:1163-73.

16. Butcher MJ, Galkina EV. Phenotypic and functional heterogeneity of macrophages and dendritic cell subsets in the healthy and atherosclerosis-prone aorta. Front Physiol. 2012;3:44.

17. de Paoli F, Staels B, Chinetti-Gbaguidi G. Macrophage phenotypes and their modulation in atherosclerosis. Circ J. 2014;78:1775-81.

18. Erbel C, Tyka M, Helmes CM, Akhavanpoor M, Rupp G, Domschke G, Linden F, Wolf A, Doesch A, Lasitschka F, Katus HA, Gleissner CA. CXCL4-induced plaque macrophages can be specifically identified by co-expression of MMP7+S100A8+ in vitro and in vivo. Innate Immun. 2015;21:255-65.

19. Azevedo RSS, de Sousa JR, Araujo MTF, Martins Filho AJ, de Alcantara BN, Araujo FMC, Queiroz MGL, Cruz ACR, Vasconcelos BHB, Chiang JO, Martins LC, Casseb LMN, da Silva EV, Carvalho VL, Vasconcelos BCB, Rodrigues SG, Oliveira CS, Quaresma JAS, Vasconcelos PFC. In situ immune response and mechanisms of cell damage in central nervous system of fatal cases microcephaly by Zika virus. Sci Rep. 2018;8:1.

20. de Lima Silveira E, de Sousa JR, de Sousa Aarão TL, Fuzii HT, Dias Junior LB, Carneiro FR, Quaresma JA. New immunologic pathways in the pathogenesis of leprosy: role for Th22 cytokines in the polar forms of the disease. J Am Acad Dermatol. 2015;72:729-30.

21. Kibbie J, Teles RM, Wang Z, Hong P, Montoya D, Krutzik S, Lee S, Kwon O, Modlin RL, Cruz D. Jagged1 instructs macrophage differentiation in leprosy. PLoS Pathog. 2016;12:e1005808.

22. Sousa JR, Sotto MN, Simões Quaresma JA. Leprosy as a complex infection: breakdown of the Th1 and Th2 immune paradigm in the immunopathogenesis of the disease. Front Immunol. 2017:8:1635.

23. Gimblet C, Loesche MA, Carvalho L, Carvalho EM, Grice EA, Artis D, Scott P. IL-22 protects against tissue damage during cutaneous leishmaniasis. PLoS One. 2015;10:e0134698.

24. Neal JW, Gasque P. The role of primary infection of Schwann cells in the aetiology of infective inflammatory neuropathies. J Inf Secur. 2016;73:402-18.

25. Zhu TH, Kamangar F, Silverstein M, Fung MA. Borderline Tuberculoid leprosy masquerading as granuloma Annulare: a clinical and histological pitfall. Am J Dermatopathol. 2017;39:296-9.

26. Sica A, Mantovani A. Macrophage plasticity and polarization: invivoveritas. J Clin Invest. 2012;122:787-95.

27. Wang N, Liang H, Zen K. 2014. Molecular mechanisms that influence the macrophage M1-M2 polarization balance. Front Immunol. 2014;5:614.

28. Oksala NKJ, Seppälä I, Rahikainen R, Mäkelä KM, Raitoharju E, Illig T, Klopp N, Kholova I, Laaksonen R, Karhunen PJ, Hytönen VP, Lehtimäki T. Synergistic Expression of Histone Deacetylase 9 and Matrix Metalloproteinase 12 in M4 Macrophages in Advanced Carotid Plaques. Eur J Vasc Endovasc Surg. 2017;53:632-40.

29. Liberale L, Dallegri F, Montecucco F, Carbone F. Pathophysiological relevance of macrophage subsets in atherogenesis. Thromb Haemost. 2017:117:7-18.

30. Nikiforov NG, Kornienko VY, Karagodin VP, Orekhov AN. Macrophage activation in atherosclerosis. Message 1: Activation of macrophages normally and in atherosclerotic lesions. Patol Fiziol Eksp Ter. 2015;3:128-31.

31. Lu X. Impact of macrophages in atherosclerosis. Curr Med Chem. 2016;23:1926-37.

32. Colin S, Chinetti-Gbaguidi G, Staels B. Macrophage phenotypes in atherosclerosis. Immunol Rev. 2014:262:153-66.

33. Erbel C, Wolf A, Lasitschka F, Linden F, Domschke G, Akhavanpoor M, Doesch AO, Katus HA, Gleissner CA. Prevalence of M4 macrophages within human coronary atherosclerotic plaques is associated with features of plaque instability. Int J Cardiol. 2015;186:219-25.

34. Ley K, Miller YI, Hedrick CC. Monocyte and macrophage dynamics during atherogenesis. Arterioscler Thromb Vasc Biol. 2011;31:1506-16.

35. Elamin AA, Stehr M, Singh M. Lipid Droplets and Mycobacterium leprae Infection. J Pathog 2012;2012:361374.

36. Kaur G, Kaur J. Multifaceted role of lipids in Mycobacterium leprae. Future Microbiol. 2017;12:315-35.

37. Mattos KA, Lara FA, Oliveira VG, Rodrigues LS, D'Avila H, Melo RC, Manso PP, Sarno EN, Bozza PT, Pessolani MC. Modulation of lipid droplets by 
Mycobacterium leprae in Schwann cells: a putative mechanism for host lipid acquisition and bacterial survival in phagosomes. Cell Microbiol. 2011;13:259-73.

38. Sousa JR, Sousa RPM, Souza Aarão TL, Dias LB Jr, Oliveira Carneiro FR, Simões Quaresma JA. Response of INOS and its relationship with IL-22 and STAT3 in macrophage activity in the polar forms of leprosy. Acta Trop. 2017;171:74-9.

39. Schrezenmeier EV, Barasch J, Budde K, Westhoff T, Schmidt-Ott KM. Biomarkers in acute kidney injury - pathophysiological basis and clinical performance. Acta Physiol. 2017;219:554-72.

40. Pruenster M, Vogl T, Roth J, Sperandio M. S100A8/A9: From basic science to clinical application. Pharmacol Ther. 2016;167:120-31.

41. Pechkovsky DV, Zalutskaya OM, Ivanov Gl, Misuno NI. Calprotectin (MRP8/14 protein complex) release during mycobacterial infection in vitro and in vivo. FEMS Immunol Med Microbiol. 2000;29:27-33.

42. Dhiman R, Venkatasubramanian S, Paidipally P, Barnes PF, Tvinnereim A, Vankayalapati R. Interleukin 22 inhibits intracellular growth of Mycobacterium tuberculosis by enhancing calgranulin A expression. J Infect Dis. 2014;209:578-87.

43. Gimblet C, Loesche MA, Carvalho L, Carvalho EM, Grice EA, Artis D, Scott P. IL-22 protects against tissue damage during cutaneous leishmaniasis. PLoS One.. 2015;10:e0134698.

44. He W, Tan RJ, Li Y, Wang D, Nie J, Hou FF, Liu Y. Matrix metalloproteinase-7 as a surrogate marker predicts renal Wnt/B-catenin activity in CKD. J Am Soc Nephrol. 2012;23:294-304.

45. Chakraborti S, Mandal M, Das S, Mandal A, Chakraborti T. Regulation of matrix metalloproteinases: an overview. Mol Cell Biochem. 2003;253:269-85.

46. Saini C, Siddiqui A, Ramesh V, Nath I. Leprosy Reactions Show Increased Th17 Cell Activity and Reduced FOXP3+ Tregs with Concomitant Decrease in TGF- $\beta$ and Increase in IL-6. PLoS Negl Trop Dis. 2016;10:e0004592.

47. Quaresma JAS, Almeida FA, Aarao TLS, Soares LPMA, Magno IMN, Fuzii HT, Libonati RMF, Xavier MB, Pagliari C, Duarte MIS. Transforming growth factor $\beta$ and apoptosis in leprosy skin lesions: possible relationship with the control of the tissue immune response in the Mycobacterium leprae infection. Microbes Infect. 2010;14:696-701.

Ready to submit your research? Choose BMC and benefit from:

- fast, convenient online submission

- thorough peer review by experienced researchers in your field

- rapid publication on acceptance

- support for research data, including large and complex data types

- gold Open Access which fosters wider collaboration and increased citations

- maximum visibility for your research: over $100 \mathrm{M}$ website views per year

At $\mathrm{BMC}$, research is always in progress.

Learn more biomedcentral.com/submissions 